\title{
Effects of neuromedin B on steroidogenesis, cell proliferation and apoptosis in porcine Leydig cells
}

\author{
Zhiyu Ma1,2, Ying Zhang', Juan Su', Sheng Yang', Wenna Qiao', Xiang Li', Zhihai Lei', Ling Cheng', Na An', \\ Wenshao Wang', Yanyan Feng' ${ }^{1}$ and Jinlong Zhang ${ }^{2}$ \\ ${ }^{1}$ College of Veterinary Medicine, Nanjing Agricultural University, Nanjing, People's Republic of China \\ ${ }^{2}$ College of Veterinary Medicine, Yangzhou University, Yangzhou, People's Republic of China \\ Correspondence should be addressed to Z Lei: lei55062@163.com
}

\begin{abstract}
Neuromedin B (NMB), a mammalian bombesin-related peptide, has numerous physiological functions, including regulating hormone secretions, cell growth, and reproduction, by binding to its receptor (NMBR). In this study, we investigated the effects of NMB on testosterone secretion, steroidogenesis, cell proliferation, and apoptosis in cultured primary porcine Leydig cells. NMBR was mainly expressed in the Leydig cells of porcine testes, and a specific dose of NMB significantly promoted the secretion of testosterone in the primary Leydig cells; moreover, NMB increased the expression of mRNA and/or proteins of NMBR and steroidogenic mediators (steroidogenic acute regulatory (STAR), CYP11A1, and HSD3B1) in the Leydig cells. In addition, specific doses of NMB promoted the proliferation of Leydig cells and increased the expression of proliferating cell nuclear antigen and Cyclin B1 proteins, while suppressing Leydig cell apoptosis and decreasing BAX and Caspase-3 protein expression. These results suggest that the NMB/NMBR system might play an important role in regulating boar reproductive function by modulating steroidogenesis and/or cell growth in porcine Leydig cells.
\end{abstract} Key Words

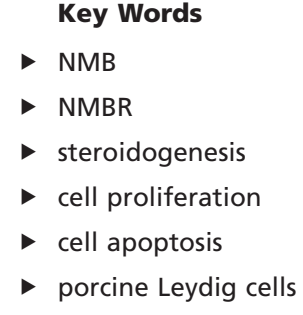

Journal of Molecular Endocrinology (2018) 61, 13-23

\section{Introduction}

Neuromedin B (NMB), a mammalian bombesin-related peptide, was originally identified in porcine spinal cord (Minamino et al. 1983) and has been found to be present mainly in the central nervous system as well as several peripheral tissues and organs, including several areas of the brain (olfactory bulb, cerebellum, brain stem and hypothalamus), spinal cord, gastrointestinal tract, pancreas, esophagus, pituitary, uterus, and testes (Wada et al. 1990, Ohki-Hamazaki 2000, Guo et al. 2015, Ma et al. 2016, Mo et al. 2017). NMB exerts numerous physiological and pharmacological effects by binding to cell-surface NMB receptor (NMBR), a G-protein coupled receptor. For example, NMB stimulates smooth muscle contraction, hormone secretion; regulates stress, anxiety, feeding, thermoregulation, energy balance, cell growth, and reproduction (Ohki-Hamazaki 2000, Ohki-Hamazaki et al. 2005, Gonzalez et al. 2008, Jensen et al. 2008, RamosAlvarez et al. 2015). Although the subtypes of mammalian bombesin receptor also include gastrin-releasing peptide receptor (GRPR) and bombesin receptor subtype 3 (BRS-3), $\mathrm{NMB}$ has a higher affinity for NMBR than the other two receptors (Jensen et al. 2008, Sayegh 2013, Ramos-Alvarez 
et al. 2015). NMB's binding to its receptor activates the G-protein coupled receptor signaling pathway, activating phospholipase C (PLC), increasing cellular inositol 1,4,5-trisphosphate $\left(\mathrm{IP}_{3}\right)$, 1,2-diacylglycerol (DAG), cytosolic $\mathrm{Ca}^{2+}$, and intracellular cAMP concentrations, resulting in related gene's expression, DNA synthesis, and/or cellular effects (hormone secretion and cell proliferation) (Ohki-Hamazaki 2000, Jensen et al. 2008).

The testes is the most important reproductive organ in male animals, and the steroidogenesis (testosterone synthesis) mainly occurs in Leydig cells (Dufau 1988). Testosterone synthesis is controlled by luteinizing hormone (LH), which is synthesized and secreted in the pituitary (Payne \& Youngblood 1995). In the testes, LH stimulates an increase in intracellular cAMP concentrations in Leydig cells, which results in steroidogenesis by regulating the expression of steroidogenic enzymes (Payne \& Youngblood 1995, Habert et al. 2001). In Leydig cells, the process of cholesterol synthesis from testosterone is as follows: cholesterol is transported from the outer mitochondrial membrane to the inner membrane under the regulation of STAR and is then converted to pregnenolone under cytochrome P450, family 11 , subfamily A, polypeptide 1 (CYP11A1/P450scc). Pregnenolone is then converted to testosterone by a series of steroidogenic enzymes, including 3 $\beta$-hydroxysteroid dehydrogenase (HSD3B1), cytochrome P450 17A1 (CYP17A1/P450c17), and 17ß-hydroxysteroid dehydrogenase (HSD17B1) (Payne \& Youngblood 1995, Lervik et al. 2011, Park et al. 2017). STAR, CYP11A1, and HSD3B1 are the key mediators of steroidogenesis. The produced testosterone plays essential roles in male sexual differentiation, reproductive development, and the initiation and maintenance of spermatogenesis (Park et al. 2017). In male rats, NMB can stimulate the activity of the hypothalamic-pituitary-gonadal (HPG) axis and regulate the secretion of gonadotrophin releasing hormone (GNRH) and LH (Boughton et al. 2013). We previously found that NMB and NMBR mRNAs are expressed in porcine testes and undergo developmental changes in the hypothalamus, pituitary, and testes of the boar during the post-natal development stages (Ma et al. 2016); therefore, we hypothesized that NMB might regulate the reproductive function in boars.

In addition, $\mathrm{NMB}$ as a growth factor can regulate the proliferation of normal tissues and many tumor cell lines through autocrine or paracrine manner after binding to its receptor (Ohki-Hamazaki 2000, Jensen et al. 2008). For example, NMBR activation can promote the proliferation of rat C6 glioma cells (Moody et al. 1995) and small-cell lung cancer cells (Moody et al. 1992), and can stimulate the growth of rat zona fasciculata cells (Malendowicz et al.
1996), mouse chondrogenic cell line ATDC5 (Saito et al. 2012), rat primary osteoblasts (Saito et al. 2013), and mice osteoclast lineage cells (Yeo et al. 2017), as well as act as mitogen in both normal and malignant colonic epithelial cells (Matusiak et al. 2005). These results suggested that the NMB/NMBR system plays a critical role in cell proliferation; therefore, we hypothesized that $\mathrm{NMB}$ might stimulate the proliferation of porcine Leydig cells.

Pigs play not only an important role in animal husbandry but are also one of the most commonly used animals experimental studies, especially as an applicationappropriate model for studies related to reproduction (Pailhoux et al. 2001). Hence, in this study, we employed the primary porcine Leydig cells as the model to study NMB's reproductive function. We first cultured primary porcine Leydig cells and detected the expression of NMB on testosterone secretion using radioimmunoassay. Subsequently, we investigated the effects of NMB on mRNA and protein expression of NMBR and steroidogenic mediators (STAR, CYP11A1 and HSD3B1) after treatment with different doses of $\mathrm{NMB}(0.01,0.1,1,10,100$, and 1000nM) in Leydig cells using real-time (RT) PCR and Western blotting, respectively. Finally, we measured the effects of NMB on the viability and apoptosis of Leydig cells using 3-(4,5-dimethyl-2-thiazolyl)-2,5-diphenyl-2H-tetrazolium bromide (MTT) and flow cytometry, respectively; also, the effects of $\mathrm{NMB}$ on the expression of proliferating cell nuclear antigen (PCNA), Cyclin B1, BAX, and Caspase-3 in primary porcine Leydig cells were measured using Western blotting. Taken together, these data suggest that the NMB/NMBR system regulates steroidogenesis as well as cell proliferation and apoptosis in primary porcine Leydig cells.

\section{Materials and methods}

\section{Animals}

Three male Xiao Meishan pigs (approximately 4 weeks old) were used for this study. All animals were fed according to the breeding standards of Chinese local pigs, as well as those of the National Research Council. The experimental studies were performed in strict accordance with the rules for experimental animals of Nanjing Agricultural University and the guidelines of the Regional Animal Ethics Committee.

\section{Isolation, purification, and culture of porcine Leydig cells}

Isolation and purification of porcine Leydig cells was performed according to the protocol previously 
described by Lervik et al. (2011). In brief, piglet testes were freshly obtained from the Xiao Meishan pigs, and immediately placed in ice-cold D-Hanks balanced salt solution. The testes were decapsulated, minced using ophthalmic scissors, and digested with $0.5 \mathrm{mg} /$ $\mathrm{mL}$ collagenase I/II (Biosharp, Hefei, China) for $30 \mathrm{~min}$ at $37^{\circ} \mathrm{C}$ in DMEM/F12 (Hyclone, Nanjing, China). The dispersed cells were filtered using a $100-\mu \mathrm{m}$ cell strainer, then pelleted by centrifugation at $400 \boldsymbol{g}$ for $10 \mathrm{~min}$. The cell pellets were resuspended, washed three times with DMEM/F12, and centrifuged at $400 \boldsymbol{g}$ for $10 \mathrm{~min}$. The final cell pellets were resuspended and purified by centrifugation through a discontinuous percoll gradient. Percoll was made isotonic by adding one volume of $8.5 \% \mathrm{NaCl}$ to nine volumes of percoll (GE Healthcare Life Sciences). This $90 \%$ percoll was further diluted with $0.85 \% \mathrm{NaCl}$ to generate $60,34,26$, and $21 \%$ percoll solutions. The solutions were layered to form a gradient (Lejeune et al. 1998). Approximately $1 \times 10^{8}$ cells from the pooled samples in $2.5 \mathrm{~mL}$ DMEM/F12 were added to each gradient and centrifuged at $400 \boldsymbol{g}$ for $30 \mathrm{~min}$. The enriched Leydig cell fractions were harvested from the $34 \%$ and $60 \%$ layers, then washed, filtered, and counted using a hemacytometer. Their viability was measured using the Trypan Blue Staining Cell Viability Assay Kit (Beyotime Biotechnology, Shanghai, China). More than $90 \%$ of the cells were viable and approximately $95 \%$ of the cells were identified as Leydig cells by cytochemical staining for 3 beta-hydroxysteroid dehydrogenase (HSD3B1) (Lervik et al. 2011, Zheng et al. 2015).

Leydig cells were cultured in 6-well cell culture cluster plates $\left(2.5 \mathrm{~mL} /\right.$ well, $1 \times 10^{6}$ cells $\left./ \mathrm{mL}\right)$ in DMEM/ F12 containing 10\% fetal bovine serum (FBS) and 1\% penicillin/streptomycin (Biosharp). Cells were incubated at $37^{\circ} \mathrm{C}$ under $5 \% \mathrm{CO}_{2}$ conditions. After $48 \mathrm{~h}$, the culture medium was replaced with DMEM/F12 containing 1\% penicillin/streptomycin, and the cells were then exposed to neuromedin $\mathrm{B}(\mathrm{NMB}$, Tocris Bioscience, $\mathrm{UK})$ at different concentrations (0.01, 0.1, 1, 10, 100 and $1000 \mathrm{nM})$. Controls were not exposed to NMB (medium blank). After $24 \mathrm{~h}$, the medium was collected and stored at $-20^{\circ} \mathrm{C}$ before measuring testosterone levels using radioimmunoassay (RIA). The cells were harvested for RT-PCR and Western blotting.

\section{Immunohistochemistry and immunocytochemistry}

The piglet testes were obtained from the Xiao Meishan pigs for immunohistochemistry (IHC). The fixation, preparation, paraffin sections and IHC procedures were performed on the testes as previously described (Ma et al. 2016). The sections were incubated with anti-HSD3B1 (sc-30820, goat polyclonal antibody, 1:100 dilution) and anti-NMBR (sc-34377, goat polyclonal antibody, 1:100 dilution) (Santa Cruz Biotechnology). In the negative control, the primary antibody was replaced with normal rabbit serum (Wuhan Boster Biological Technology Co., China). The images were captured using the OLYMPUS BX43 microscope (Olympus).

Leydig cells were cultured in 12-well cell culture cluster plates $\left(1 \mathrm{~mL} /\right.$ well, $1 \times 10^{6}$ cells $\left./ \mathrm{mL}\right)$ in DMEM/F12 containing $10 \%$ FBS and 1\% penicillin/streptomycin, incubated for $48 \mathrm{~h}$ and fixed for immunocytochemistry (ICC). The cells were fixed with $4 \%$ paraformaldehyde for $30 \mathrm{~min}$ and washed three times in $0.1 \mathrm{M}$ PBS. The ICC procedure was similar to that previously described by Li et al. (2013). The cells were incubated with anti-HSD3B1 (1:100 dilution) and anti-NMBR (1:100 dilution). For the negative control, normal rabbit serum was utilized instead of the primary antibody. The images were observed using the OLYMPUS BX43 microscope.

\section{Radioimmunoassay}

The concentration of testosterone was measured using an Iodine [125I] Testosterone Radioimmunoassay Kit (Beijing North Biotechnology Research Institute, China) according to the manufacturer's instruction. The intraand inter-assay coefficients of variation were $3.5 \%$ and $6.9 \%$ for testosterone estimations, respectively. The assay sensitivity for testosterone estimation was $0.02 \mathrm{ng} / \mathrm{mL}$.

\section{Relative real-time PCR}

Total RNA was extracted using an RNA isolater (Vazyme Biotech Co., China) according to the manufacturer's instruction. Then, the RNA concentration and quality were detected using the ND2000 Spectrophotometer (Thermo Scientific). The RNA integrity was verified using RNA gel electrophoresis, and the 18S and 28S rRNA bands were separated without a leading smear. Subsequently, cDNA was synthesized with HiScript Reverse Transcriptase for qPCR (+gDNA wiper) (Vazyme Biotech Co.), depending on the manufacturer's direction.

The RT-PCR reactions were performed according to the protocol described by Ma et al. (2016). In brief, RT-PCR was conducted using the CFX Connect RealTime System (Bio-Rad), and the SYBR Green Master Mix Kit (Vazyme Biotech Co., Nanjing, China) according to the manufacturer's instruction. The primer sequences 
for the genes are listed in Table 1 , and the $\beta$-actin gene was used as an internal control. The mRNA quantities of the different genes were expressed as a proportion of the $\beta$-actin mRNA quantity using the $2^{-\Delta \Delta C t}$ method (Livak \& Schmittgen 2001).

\section{Western blotting}

After treating the Leydig cells (described in 'Isolation, purification, and culture of porcine Leydig cells' section), the cells were washed using cold PBS and lysed in RIPA Lysis Buffer (Beyotime Biotechnology), according to the manufacturer's instruction. Equal amounts of the proteins $(20 \mu \mathrm{g})$ were fractionated using $10 \%$ SDS-PAGE, and then transferred onto nitrocellulose membranes. The membranes were blocked using 5\% skimmed milk powder for $2 \mathrm{~h}$ and incubated overnight with primary antibody at an appropriate dilution at $4^{\circ} \mathrm{C}$. Western blot analysis was performed with the following antibodies: anti-NMBR (dilution 1:1000), anti-HSD3B1 (dilution 1:1000), anti-CYP11A1 (orb156513, rabbit polyclonal antibody, dilution 1:1000) (Biorbyt, UK), anti-StAR (bs-20387R, dilution 1:1000) (Bioss, Beijing, China), antiPCNA (sc-7907, dilution 1:1000), anti-Cyclin B1 (sc-595, dilution 1:1000), anti-BAX (sc-6236, dilution 1:500), antiCaspase-3 (sc-7148, dilution 1:1000) (rabbit polyclonal antibody, Santa Cruz Biotechnology) and anti- $\beta$-actin (HC201, mouse monoclonal antibody, dilution 1:5000) (Transgen Biotech, Beijing, China). The membranes were then incubated with horseradish peroxidaseconjugated rabbit anti-goat IgG (dilution 1:10,000), goat anti-mouse IgG $(1: 10,000)$ and goat anti-rabbit IgG $(1: 10,000)$ (Boster, Wuhan, China) secondary antibodies, respectively. Specific signals were detected using the ECL Chemiluminescent Chromogenic Kit (Vazyme Biotech Co.) after which the membranes were exposed to Tanon
5200 Multi (Tanon Science \& Technology Co., Shanghai, China). Densitometric quantification was performed using the ImageJ software (National Institutes of Health), with $\beta$-actin as the internal control for normalization.

\section{Cell viability (MTT) assay}

To assess the effect of NMB on cell viability, cells were seeded in a 96-well plate $\left(100 \mu \mathrm{L} /\right.$ well, $3 \times 10^{4}$ cells $\left./ \mathrm{mL}\right)$ and grown for $48 \mathrm{~h}$. The cells were starved for $24 \mathrm{~h}$ before treatment with different concentrations of $\mathrm{NMB}$ in starvation medium for $24 \mathrm{~h}$. Controls were not exposed to NMB (medium blank). Cell viability was measured using the MTT Cell Proliferation and Cytotoxicity Assay Kit (Beyotime) according to the manufacturer's protocol, and the absorbance was read at $570 \mathrm{~nm}$ on a Microplate Reader (Bio-Rad).

\section{Cell apoptosis (FITC) assay}

Cells undergoing apoptosis were assessed using the FITC Annexin V Apoptosis Detection Kit I (BD Biosciences, USA), according to the manufacturer's manual. Briefly, the cells were washed twice with cold PBS and resuspended in $1 \times$ binding buffer at a concentration of $1 \times 10^{6}$ cells $/ \mathrm{mL}$, after which $100 \mu \mathrm{L}$ of the solution (approximately $1 \times 10^{5}$ cells) was transferred to a 5 -mL culture tube and incubated with $5 \mu \mathrm{L}$ FITC Annexin $\mathrm{V}$ and $5 \mu \mathrm{L}$ propidium iodide (PI) for $15 \mathrm{~min}$ in the darkness. The staining profiles were then detected using flow cytometry and analyzed with FlowJo software.

\section{Statistical analysis}

To identify the significant differences, the data were analyzed using GraphPad Prism 5. All data were presented

Table 1 Primers and annealing temperature for real-time PCR.

\begin{tabular}{|c|c|c|c|c|}
\hline Genes & GenBank ID & Primers sequences $\left(5^{\prime}-3^{\prime}\right)$ & Annealing $\left({ }^{\circ} \mathrm{C}\right)$ & Length $(b p)$ \\
\hline \multirow[t]{2}{*}{$N M B R$} & KM058699 & Forward: TAGGCCACATGATTGTCAC & 60 & 136 \\
\hline & & Reverse: GACTTCCTTCCGCAACAGA & & \\
\hline \multirow[t]{2}{*}{ STAR } & NM_213755.2 & Forward: AGTGGAACCCCAGTGTCAAG & 60 & 198 \\
\hline & & Reverse: GCTCAGGCATCTCTCCAAAG & & \\
\hline \multirow[t]{2}{*}{ CYP11A1 } & NM_214427.1 & Forward: CACCCCATCTCCGTGACC & 60 & 101 \\
\hline & & Reverse: GCATAGACGGCCACTTGTACC & & \\
\hline \multirow[t]{2}{*}{ HSD3B1 } & NM_001004049.1 & Forward: TTCAATCGCCACTTCGTGACC & 60 & 144 \\
\hline & & Reverse: CTTCACCAGGGAGCCAACCCA & & \\
\hline \multirow[t]{2}{*}{ ACTB } & XM_003124280.2 & Forward: CTCCATCATGAAGTGCGACGT & 60 & 114 \\
\hline & & Reverse: GTGATCTCCTTCTGCATCCTGTC & & \\
\hline
\end{tabular}

NMBR and ACTB primers were obtained from a previous study (Ma et al. 2016); STAR and HSD3B1 primers were designed from the STAR and HSD3B1 gene sequences; CYP11A1 primers were obtained from a previous study (Lervik et al. 2011). 
using the means \pm standard error of the mean (s.E.M.). The statistical analysis was analyzed using one-way ANOVA and the multiple comparisons test (Tukey's) with SPSS Statistics 19.0 (SPSS, IBM). Each pig was used to generate a pool of cells, and 3 independent pools of cells were used for analysis.

\section{Results}

\section{Expression of NMBR in the Leydig cells of testes}

We had previously found that $N M B$ and $N M B R$ mRNAs are expressed not only in pig testes, but also in the reproductive axis of the boar during post-natal development (Ma et al. 2016). To study the function of NMB in testes, we first investigated the distribution of NMBR in pig testes. IHC results showed that the NMBR protein was mainly distributed in the Leydig cells of testes (Fig. 1B). Subsequently, ICC results showed that NMBR was expressed in uncultured Leydig cells (Fig. 1E) and primary Leydig cells cultured for $48 \mathrm{~h}$ (Fig. 1H). HSD3B1 was expressed in testes (Fig. 1A) and Leydig cells (Fig. 1D and G) as positive control. No immunoreactivity was found in the negative controls (Fig. 1C, F and I). These results indicated that NMB might affect testicular function through the Leydig cells.

\section{Effects of NMB on testosterone secretion and the expression of NMBR}

Testicular Leydig cells control the synthesis of testosterone, the male sex hormone (Dufau 1988). To study whether exogenous NMB affects the secretion of testosterone, we evaluated testosterone concentrations in the incubation medium of primary porcine Leydig cells after treatment with different doses of NMB. Radioimmunoassay results showed that $\mathrm{NMB}$ treatment caused a dose-dependent increase in testosterone secretion (Fig. 2A). We found that, compared with the control group, Leydig cells treated with 1 and $10 \mathrm{nM}$ NMB showed a significant increase in the secretion of testosterone $(P<0.01)$, with $1 \mathrm{nM}$ having the greatest effect; and other doses showing no significant increase $(P>0.05)$. The results showed that a specific dose of $\mathrm{NMB}$ can promote testosterone synthesis in primary porcine Leydig cells.

NMB exerts its effect by binding to NMBR (OhkiHamazaki 2000); therefore, we investigated the expression levels of NMBR mRNA and protein in primary porcine Leydig cells after treating with different doses of NMB. As shown in Fig. 2B, compared with the control group, different doses of NMB increased the expression of NMBR mRNA; both $0.1 \mathrm{nM}$ and $1 \mathrm{nM} \mathrm{NMB}$ significantly increased the $N M B R$ mRNA expression $(P<0.01)$, and at $1 \mathrm{nM}$, the expression level of NMBR mRNA was the highest; in addition, the
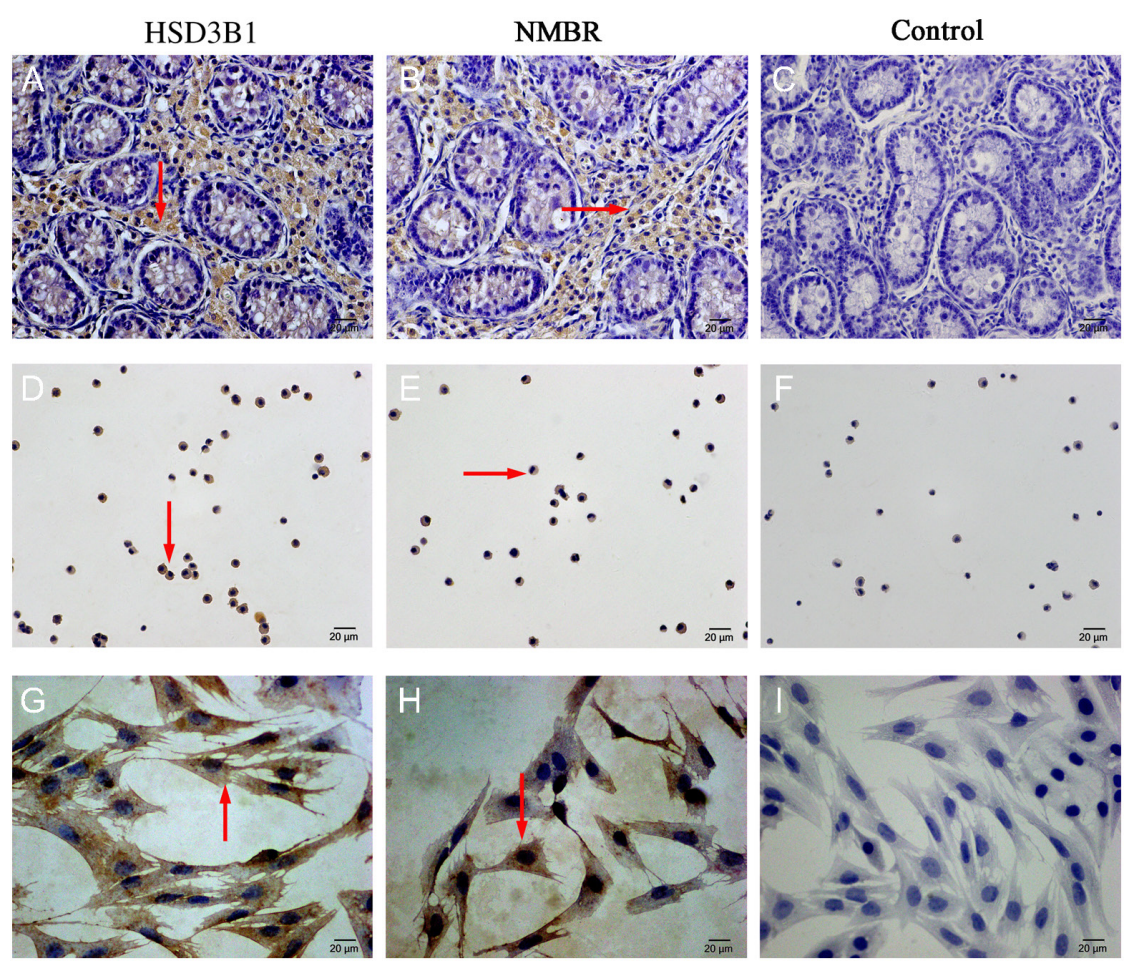

\section{Figure 1}

Distribution of NMBR in Leydig cells of the testes. ( $A$ and $B$ ) Distribution of HSD3B1 and NMBR in the testes. Strong immunoreactivity of the HSD3B1 (A) and NMBR (B) proteins were mainly distributed in the Leydig cells (denoted by an red arrow); (D and E) distribution of HSD3B1 and NMBR in the uncultured Leydig cells. The HSD3B1 (D) and NMBR (E) immunoreactivity were detected in the Leydig cells (denoted by an red arrow); ( $\mathrm{G}$ and $\mathrm{H}$ ) distribution of HSD3B1 and NMBR in the primary Leydig cells cultured for 48h. Considerable HSD3B1 (G) and NMBR (H) immunoreactivity were found in the primary cultured Leydig cells (denoted by an red arrow). Negative controls in the testes (C), Leydig cells (F) and primary cultured Leydig cells (I). Scale bars in (A, B, C, D, E and F) $=20 \mu \mathrm{m},(\mathrm{G}, \mathrm{H}$ and I) (photos under the oil mirror) $=20 \mu \mathrm{m}$. A full color version of this figure is available at https://doi. org/10.1530/JME-17-0242. http://jme.endocrinology-journals.org https://doi.org/10.1530/JME-17-0242
() 2018 Society for Endocrinology Published by Bioscientifica Ltd. Printed in Great Britain 
A

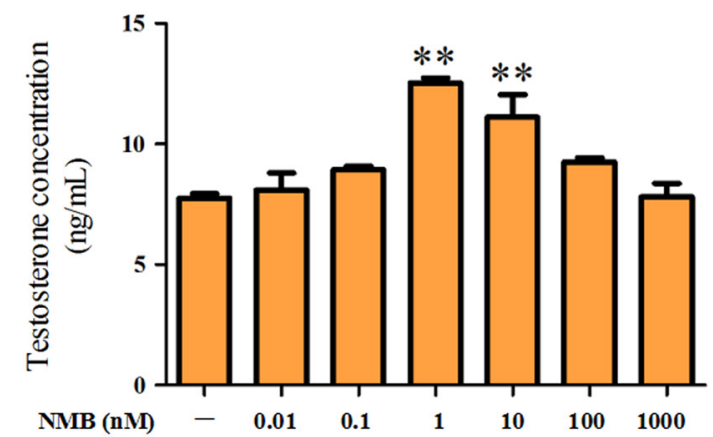

B Relative NMBR mRNA expression in the Leydig cells
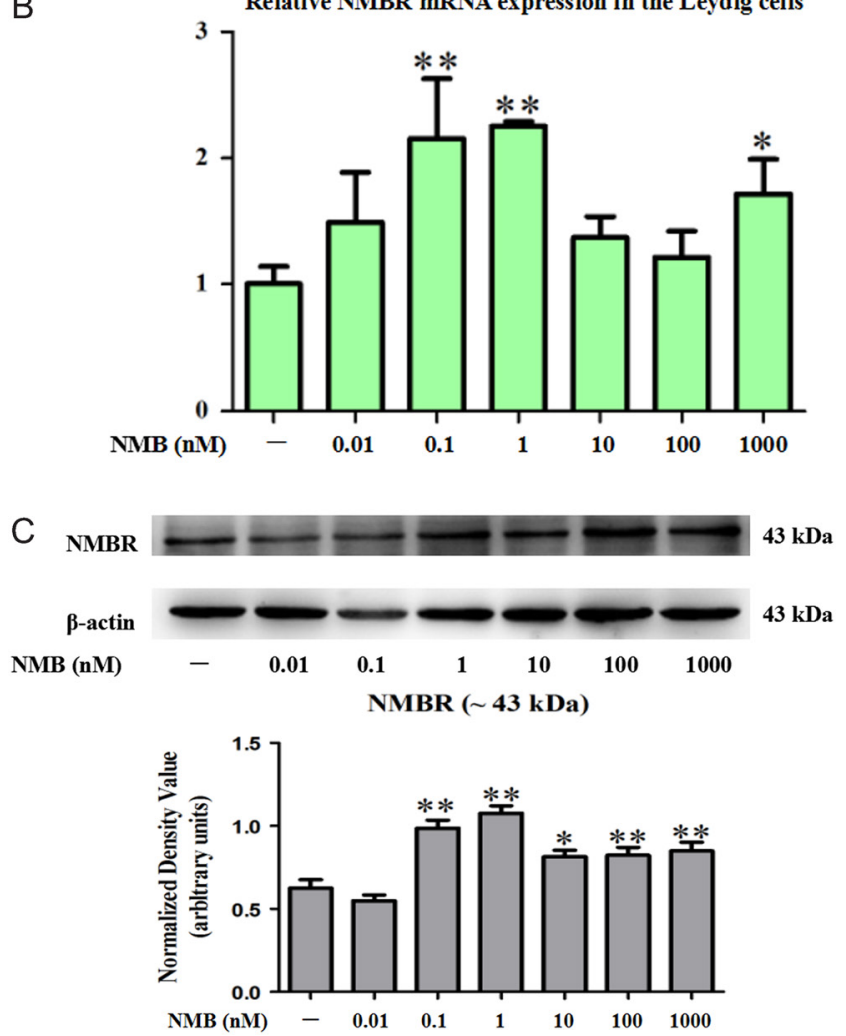

Figure 2

The effects of NMB on testosterone secretion, as well as NMBR mRNA and protein expression in primary cultured porcine Leydig cells. (A) The stimulatory effect of NMB on testosterone secretion in the cultured Leydig cells $(n=4)$. (B) The stimulatory effect of NMB on NMBR (B) mRNA expression in the cultured Leydig cells $(n=3)$. (C) The stimulatory effect of NMB on NMBR protein expression in the cultured Leydig cells was detected by Western blot analysis (upper panel). Normalized density value of the Western blots (lower panel). ' - ' as the control group. Values are means ( \pm s.E.M.). Compared with control group, asterisk indicates a significant difference. ${ }^{*} P<0.05, * * P<0.01$. A full color version of this figure is available at https://doi.org/10.1530/JME-17-0242.

highest dose $(1000 \mathrm{nM})$ of $\mathrm{NMB}$ also significantly promoted the expression of NMBR mRNA $(P<0.05)$, but other doses had no significant effect $(P>0.05)$.

As shown in Fig. 2C, Western blot analysis showed that NMBR immunoblot revealed a single band at $\sim 43 \mathrm{kDa}$ (upper panel). Densitometric analysis of the Western blots showed that, except for $0.01 \mathrm{nM} \mathrm{NMB}$, all other doses significantly increased the expression of NMBR protein when compared with the control group $(P<0.01$ or $P<0.05)$, and the peak level of NMBR protein was found at $1 \mathrm{nM}$ NMB (lower panel). Taken together, these results indicated that $\mathrm{NMB}$ might modulate testosterone synthesis by activating NMBR in primary porcine Leydig cells.

\section{Effects of NMB on steroidogenic mediators mRNA and protein expression}

To further understand the molecular mechanism underlying the NMB/NMBR system mediated enhancement of testosterone synthesis, the effects of $\mathrm{NMB}$ on steroidogenic mediators (STAR, CYP11A1 and HSD3B1) mRNA and protein expression were elucidated in primary porcine Leydig cells treated with NMB. RT-PCR analysis showed that different doses of NMB resulted in an increase in the expression levels of STAR, CYP11A1 and HSD3B1 mRNA compared with that of the control group, and these expression levels were highest at $1 \mathrm{nM} \mathrm{NMB}(P<0.01$, $P<0.01$, and $P<0.05$, respectively) (Fig. $3 \mathrm{~A}, \mathrm{C}$ and $\mathrm{E}$ ).

As shown in Fig. 3B, C and D, immunoblots for STAR, CYP11A1 and HSD3B1 revealed a single band at $\sim 32$, $\sim 53$ and $\sim 42 \mathrm{kDa}$, respectively (upper panel). Moreover, densitometric analysis of Western blots of the samples of cells treated with different doses of NMB revealed a marked variation in the expression of STAR, CYP11A1 and HSD3B1 proteins (lower panel). We found that, except for $0.01 \mathrm{nM}, \mathrm{NMB}$ significantly increased the expression of STAR protein $(P<0.01)$; at $10 \mathrm{nM} \mathrm{NMB}$, the expression level of STAR protein were the highest (Fig. 3B). Similar to the expression of CYP11A1 and HSD3B1 mRNAs, different doses of NMB also resulted in an increase in the expression of CYP11A1 and HSD3B1 proteins; at $1 \mathrm{nM} \mathrm{NMB}$, the expression levels of CYP11A1 and HSD3B1 protein were the highest $(P<0.01)$ (Fig. 3D and F). Taken together, these results indicate that the NMB/NMBR system might promote testosterone production by regulating the expression of steroidogenic mediators in primary porcine Leydig cells.

\section{Effect of NMB on cell proliferation}

Because NMB can act as a factor in regulating cell growth, we evaluated whether NMB affects the viability of primary porcine Leydig cells. Cell viability (MTT) assay showed that (Fig. 4A), compared with the control group, different 
A

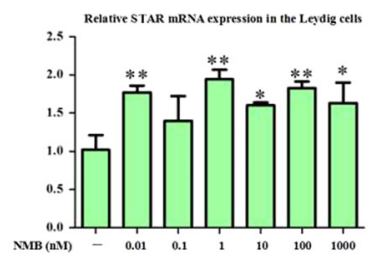

C

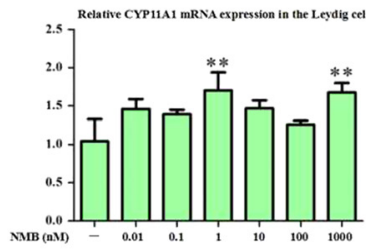

E

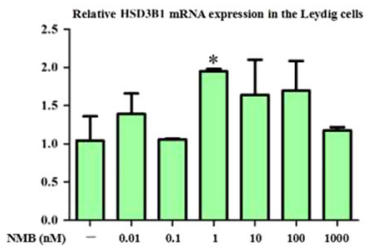

B

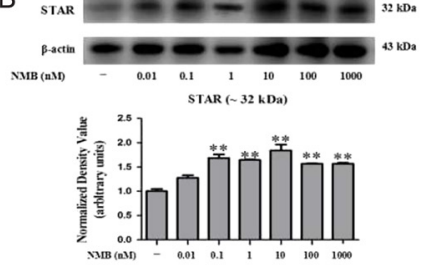

D
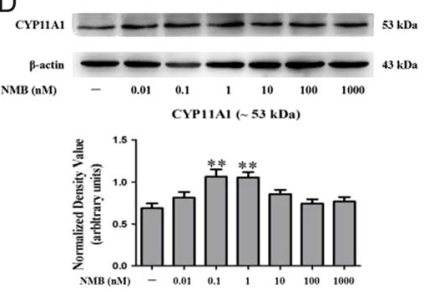

$\mathrm{F}$
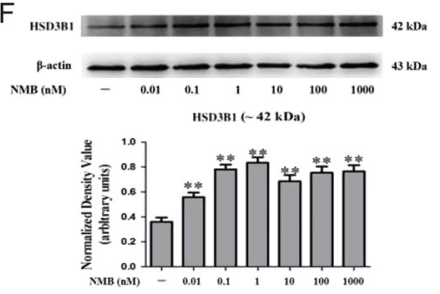

Figure 3

The effects of NMB on steroidogenic gene mRNA and protein (STAR, CYP11A1 and HSD3B1) expression in primary cultured porcine Leydig cells $(n=3)$. (A, C and E) The stimulatory effect of NMB on steroidogenic gene (STAR (A), CYP11A1 (C) and HSD3B1 (E)) mRNA expressions in the cultured Leydig cells. ( $B, D$ and $F$ ) The stimulatory effect of NMB on the steroidogenic proteins (STAR (B), CYP11A1 (D) and HSD3B1 (F)) in the cultured Leydig cells were detected via Western blot analysis ( $B, D$, and $F$ upper panel, respectively). Normalized density value of the Western blots (B, D and F lower panel, respectively). '-' as the control group. Values are means ( \pm S.E.M.). Compared with control group, asterisk indicates a significant difference. ${ }^{*} P<0.05, * * P<0.01$. A full color version of this figure is available at https://doi.org/10.1530/JME-17-0242.

doses of NMB stimulated viability of Leydig cells; except for $0.01 \mathrm{nM}$ (Min) and 1000 nM (Max) NMB, other doses of NMB significantly stimulated cell viability $(P<0.01$ or $P<0.05)$; at $1 \mathrm{nM} \mathrm{NMB}$, the viability was highest.

Subsequently, we further detected the effect of NMB on PCNA and cyclin B1 protein expression in primary porcine Leydig cells. Western blot analysis (Fig. 4B and C) showed a single band at $\sim 36 \mathrm{kDa}$ and $\sim 60 \mathrm{kDa}$, respectively, for PCNA and Cyclin B1 (upper panel). In addition, densitometric analysis of the Western blots showed that (lower panel) different doses of NMB significantly stimulated the expression of PCNA (except for $100 \mathrm{nM} \mathrm{NMB}$ ) and Cyclin B1 (except for $10 \mathrm{nM} \mathrm{NMB})$ proteins $(P<0.01$ or $P<0.05)$, respectively. PCNA showed highest expression at $0.1 \mathrm{nM} \mathrm{NMB}$, while Cyclin B1 showed highest expression at $1 \mathrm{nM}$ NMB. Taken together, these data suggest that the NMB/NMBR

A
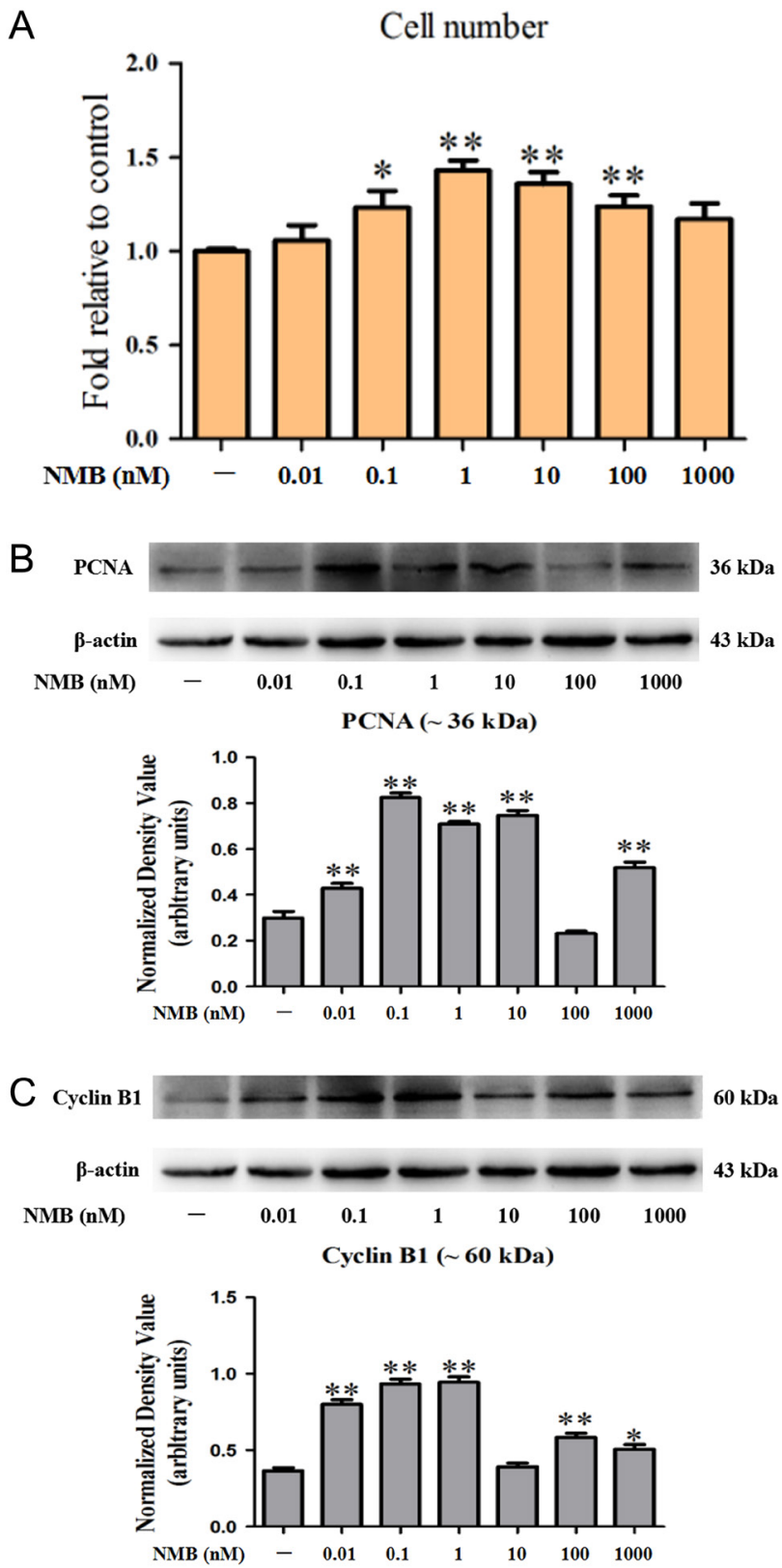

Figure 4

The effect NMB on cell proliferation in primary porcine Leydig cells. (A) Primary porcine Leydig cells were treated with different doses of NMB for $24 \mathrm{~h}$. Then cell viability was measured using MTT assay $(n=6)$. (B and C) The stimulatory effect of different doses of NMB on PCNA (B) and Cyclin B1 (C) proteins in the primary cultured Leydig cells were detected by Western blot analysis (B and $C$ upper panel, respectively), and normalized density value of the Western blots ( $B$ and $C$ lower panel, respectively) $(n=3)$. ' - ' as the control group. Values are means ( \pm s.E.M.). Compared with control group, asterisk indicates a significant difference. ${ }^{*} P<0.05$,

$* * P<0.01$. A full color version of this figure is available at https://doi. org/10.1530/JME-17-0242.

system might promote the proliferation of primary porcine Leydig cells by regulating PCNA and Cyclin B1 expression. 


\section{Effect of NMB on cell apoptosis}

Next, we detected whether NMB affects the apoptosis of primary porcine Leydig cells using flow cytometry as described in 'Cell apoptosis (FITC) assay' section. As shown in Fig. 5A (left panel), compared with the control group, a significant decrease in the number of cells that underwent apoptosis was observed after treating with different doses of NMB. The mean cell number in the sub-G1 phase of the cell cycle was also significantly lower in the NMB-treated Leydig cells compared to that in the non-treated cells (Fig. 5A, right panel; $P<0.01)$.

Next, we examined the effect of NMB on BAX and Caspase-3 protein expression in primary porcine Leydig cells. As shown in Fig. 5B and C, immunoblots for BAX and Caspase-3 revealed a single band at $\sim 23 \mathrm{kDa}$ and $\sim 32 \mathrm{kDa}$, respectively (upper panel). Moreover, densitometric analysis of the Western blots indicated that $0.01-1000 \mathrm{nM}$ NMB significantly decreased the expression of BAX protein $(P<0.01)$, and $0.1-100 \mathrm{nM}$ NMB significantly reduced the expression of Caspase-3 protein $(P<0.01)$ (lower panel). Taken together, these results suggest that the NMB/NMBR system can suppress the apoptosis of primary porcine Leydig cells and modulate the expression of BAX and Caspase-3.

\section{Discussion}

The expression and function of the NMB/NMBR system have been studied extensively in humans, rats and mice. NMB exerts several biological functions by binding
NMBR, such as stimulating smooth muscle, mediating stress and fear reactions, regulating feeding, regulating temperature, energy balance, regulating endocrine and/ or exocrine secretions and promoting cell growth (OhkiHamazaki 2000, Jensen et al. 2008). In addition, NMB can stimulate the hypothalamic-pituitary-gonadal (HPG) axis in male rats, which indicates that NMB can also regulate reproduction (Boughton et al. 2013); however, little is known about the physiological functions of NMB in pigs, except that it can contract the porcine lower esophageal sphincter (Tsai et al. 2015). We had previously found that $N M B$ and NMBR mRNAs are expressed in pig testes and that they exhibit developmental changes in the gonadal axis of boars (Ma et al. 2016); therefore, we speculated that the NMB/NMBR system might have an impact on the reproductive function of boars.

Through IHC, we found that NMBR was mainly distributed in the Leydig cells in porcine testes. Subsequently, we isolated and cultured primary porcine Leydig cells (Lejeune et al. 1998, Lervik et al. 2011) and measured the viability and purity of these cells using trypan blue and HSD3B1 cytochemical staining (Lervik et al. 2011, Zheng et al. 2015), respectively. Using IHC, we found that NMBR was expressed in Leydig cells; therefore, we believed that NMB in the Leydig cells had an effect. In 3- to 5-week-old pig testes, the percentage and volume of Leydig cells are high and the Leydig cells in primary culture retain steroidogenic capacity; additionally, between birth and 1 month of age, the number of Leydig cells per testis showed a significant increase (Franca et al. 2000); therefore, researchers usually study steroidogenesis in a primary culture of immature porcine Leydig cells as
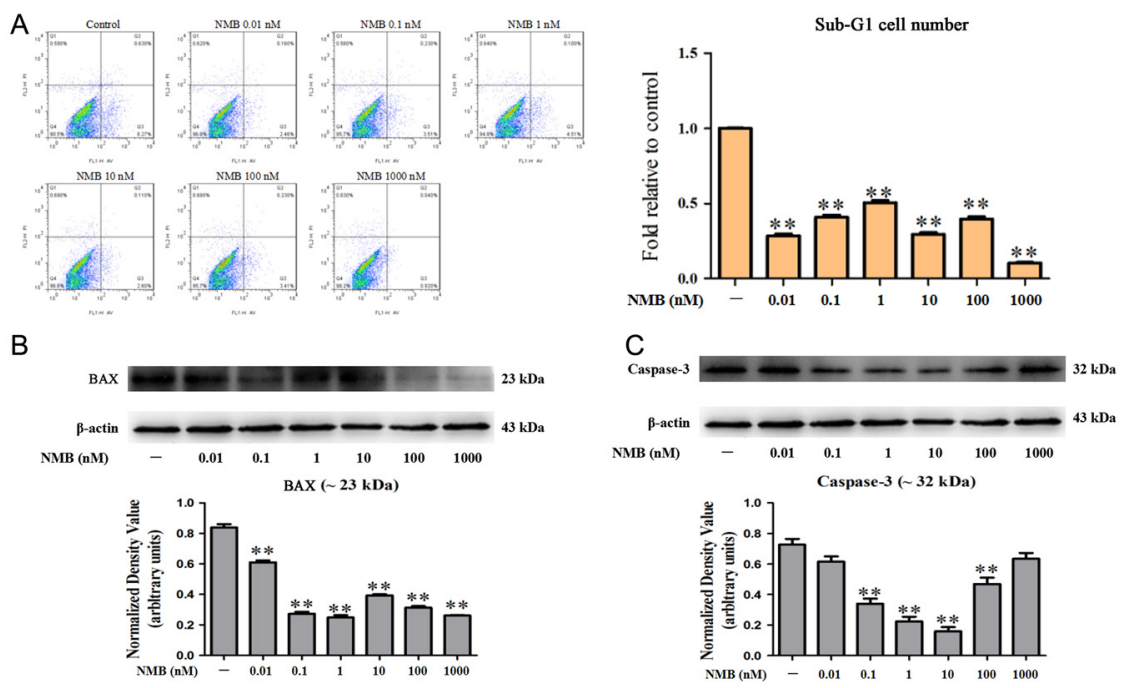
Figure 5
The effect of NMB on cell apoptosis in primary porcine Leydig cells $(n=3)$. (A) Primary porcine Leydig cells were treated with different doses of NMB for $24 \mathrm{~h}$, and then cell apoptosis was evaluated using flow cytometry. (Left panel) representative images of flow cytometry analysis in Leydig cells; (right panel) percentage of apoptotic cells in Leydig cells. (B and C) The stimulatory effect of different doses of NMB on BAX (B) and Caspase-3 (C) proteins in the primary cultured Leydig cells were detected by Western blot analysis (B and C upper panel, respectively), and normalized density value of the Western blots ( $B$ and C lower panel, respectively). ' - ' as the control group. Values are means ( \pm S.E.M.). Compared with control group, asterisk indicates a significant difference. ${ }^{*} P<0.05, * * P<0.01$. A full color version of this figure is available at https:// doi.org/10.1530/JME-17-0242.


models, which study the steroidogenesis of adult porcine Leydig cells and the development of Leydig cells (Bernier et al. 1983, Lejeune et al. 1998, Mauduit et al. 2001, Fombonne et al. 2003, Nakajima et al. 2005, Honda et al. 2008, Lervik et al. 2011, Castellanos et al. 2013). In this study, we employed immature porcine Leydig cells to study the effects of $\mathrm{NMB}$ on boar reproduction and treated the primary culture with different doses $(0.01-1000 \mathrm{nM})$ of NMB (Saito et al. 2013). The results of our study revealed that 1 and $10 \mathrm{nM}$ NMB significantly increased testosterone secretion in Leydig cells.

The production of testosterone plays an important role in the reproductive function of male animals (Park et al. 2017); therefore, we wanted to determine how NMB promotes testosterone production. Using RT-PCR and Western blotting, we found that NMB could promote the expression of NMBR mRNA and protein in primary porcine Leydig cells. It is known that NMB binding to NMBR activates PLC, and increases cellular $\mathrm{IP}_{3}, \mathrm{DAG}$ and $\mathrm{Ca}^{2+}$ concentrations. DAG, as a secondary messenger, activates protein kinase $\mathrm{C}$ and increases intracellular cAMP concentration, which eventually results in DNA synthesis and/or cellular effects (Ohki-Hamazaki 2000, Jensen et al. 2008). In the testes, LH combines its receptor (LHR, the G-protein coupled receptor) on the surface of Leydig cells, increases intracellular cAMP concentration and results in steroidogenesis by facilitating the expression of steroidogenic mediators, including STAR, CYP11A1, HSD3B1, CYP17A1 and 17 $\beta$ HSD (Payne \& Youngblood 1995, Habert et al. 2001); therefore, we believe that the NMB/NMBR system might also modulate the expression of steroidogenic mediators.

To further understand the molecular mechanism underlying the NMB/NMBR system mediated enhancement of testosterone synthesis, we investigated the effects of NMB on STAR, CYP11A1 and HSD3B1 mRNA and protein expression using RT-PCR and Western blotting, respectively. We found that specific doses, particularly 1-nM NMB, significantly increases the expression of mRNAs and/or protein of STAR, CYP11A1 and HSD3B1. Although, the mechanisms of action of STAR are not entirely known, studies showed that STAR supports the cholesterol transfer function of the protein, and STAR has to be phosphorylated to produce its activity (Arakane et al. 1997, Mauduit et al. 2001). These results suggest that NMB might promote cholesterol transport to the inner mitochondrial membrane and move it toward CYP11A1 by increasing the concentration of STAR. Then, the increased
CYP11A1 catalyzes the conversion of cholesterol into pregnenolone and, finally, a series of enzymatic reactions, particularly increased HSD3B1, converts pregnenolone into testosterone (Payne \& Youngblood 1995, Lervik et al. 2011, Park et al. 2017). These results provide a theoretical basis for further research on the reproductive function of NMB in boars.

As mentioned, NMB can promote cell growth and might also affect the proliferation of Leydig cells. Through cell viability (MTT) assay, we found that NMB could promote the proliferation of primary porcine Leydig cells. PCNA plays an important role in cell cycle progression, DNA replication and DNA repair. In addition, Cyclin B1 is involved in the regulation of cell cycle and its expression increases during cell proliferation. It has been noted that the expression of PCNA and Cyclin B1 is associated with the proliferation and transition of germ cells through the late G1 and S phases of mitosis (Chaffin et al. 2001, Meloche \& Pouyssegur 2007). The results of Western blotting also showed that NMB increased the expression of PCNA and Cyclin B1 proteins in primary porcine Leydig cells. It was further demonstrated that the NMB/ NMBR system could promote the proliferation of Leydig cells; however, the specific regulatory mechanism remains to be elucidated.

Additionally, using flow cytometry, we found that NMB significantly suppressed the apoptosis of primary porcine Leydig cells. It was noted that NMB/ NMBR silencing increases the apoptosis of osteoclast precursors (Yeo et al. 2017). BAX and Caspase-3 play an important role in the process of cell apoptosis, and their expression was found to be increased during cell apoptosis; however, we found that NMB could markedly decrease the expression of BAX and Caspase-3 proteins in primary porcine Leydig cells. These findings indicate that the NMB/NMBR might also play a pivotal role in the apoptosis of Leydig cells.

In conclusion, our findings show that the NMB/ NMBR system stimulates the synthesis and release of testosterone by regulating the expression of steroidogenic mediators STAR, CYP11A1 and HSD3B1 in primary porcine Leydig cells. Furthermore, the NMB/NMBR system also promotes cell proliferation and increases the expression of PCNA and Cyclin B1, as well as suppresses cell apoptosis and decreases the expression of BAX and Caspase-3. Taken together, these findings suggest that the NMB/NMBR system might be involved in regulating the reproductive organ development and function in boars. 


\section{Declaration of interest}

The authors declare that there is no conflict of interest that could be perceived as prejudicing the impartiality of the research reported.

\section{Funding}

This work was supported by National Nature Science Foundation of China (31372388) and Project Funded by the Priority Academic Program Development of Jiangsu Higher Education Institutions (PAPD).

\section{References}

Arakane F, King SR, Du Y, Kallen CB, Walsh LP, Watari H, Stocco DM \& Strauss JF 3rd 1997 Phosphorylation of steroidogenic acute regulatory protein (StAR) modulates its steroidogenic activity. Journal of Biological Chemistry 272 32656-32662. (https://doi.org/10.1074/ jbc.272.51.32656)

Bernier M, Gibb W, Haour F, Collu R, Saez JM \& Ducharme JR 1983 Studies with purified immature porcine Leydig cells in primary culture. Biology of Reproduction 29 1172-1178. (https://doi. org/10.1095/biolreprod29.5.1172)

Boughton CK, Patel SA, Thompson EL, Patterson M, Curtis AE, Amin A, Chen K, Ghatei MA, Bloom SR \& Murphy KG 2013 Neuromedin B stimulates the hypothalamic-pituitary-gonadal axis in male rats. Regulatory Peptides 187 6-11. (https://doi.org/10.1016/j. regpep.2013.10.002)

Castellanos CG, Sorvik IB, Tanum MB, Verhaegen S, Brandt I \& Ropstad E 2013 Differential effects of the persistent DDT metabolite methylsulfonyl-DDE in nonstimulated and LH-stimulated neonatal porcine Leydig cells. Toxicology and Applied Pharmacology 267 247-255. (https://doi.org/10.1016/j.taap.2012.12.022)

Chaffin CL, Schwinof KM \& Stouffer RL 2001 Gonadotropin and steroid control of granulosa cell proliferation during the periovulatory interval in rhesus monkeys. Biology of Reproduction 65 755-762 (https://doi.org/10.1095/biolreprod65.3.755)

Dufau ML 1988 Endocrine regulation and communicating functions of the Leydig cell. Annual Review of Physiology 50 483-508. (https://doi. org/10.1146/annurev.ph.50.030188.002411)

Fombonne J, Csaba Z, von Boxberg Y, Valayer A, Rey C, Benahmed M, Dournaud P \& Krantic S 2003 Expression of somatostatin receptor type-2 (sst2A) in immature porcine Leydig cells and a possible role in the local control of testosterone secretion. Reproductive Biology and Endocrinology 1 19. (https://doi.org/10.1186/1477-7827-1-19)

Franca LR, Silva VA Jr, Chiarini-Garcia H, Garcia SK \& Debeljuk L 2000 Cell proliferation and hormonal changes during postnatal development of the testis in the pig. Biology of Reproduction $\mathbf{6 3}$ 1629-1636. (https://doi.org/10.1095/biolreprod63.6.1629)

Gonzalez N, Moody TW, Igarashi H, Ito T \& Jensen RT 2008 Bombesinrelated peptides and their receptors: recent advances in their role in physiology and disease states. Current Opinion in Endocrinology, Diabetes and Obesity 15 58-64. (https://doi.org/10.1097/ MED.0b013e3282f3709b)

Guo TT, Su J, Ma ZY, Ma JX, Jin MM, Li X \& Lei ZH 2015 Cloning of Neuromedin $B$ and its receptor in the rabbit and generating a polyclonal antibody to the Neuromedin B protein. Gene 564 21-28. (https://doi.org/10.1016/j.gene.2015.03.038)

Habert R, Lejeune H \& Saez JM 2001 Origin, differentiation and regulation of fetal and adult Leydig cells. Molecular and Cellular Endocrinology 179 47-74. (https://doi.org/10.1016/S03037207(01)00461-0)

Honda Y, Ohno S \& Nakajin S 2008 Leydig cells from neonatal pig testis abundantly express 11 beta-hydroxysteroid dehydrogenase (11betaHSD) type 2 and effectively inactivate cortisol to cortisone. Journal of
Steroid Biochemistry and Molecular Biology 108 91-101. (https://doi. $\operatorname{org} / 10.1016 / \mathrm{j} . j \mathrm{sbmb} .2007 .07 .003)$

Jensen RT, Battey JF, Spindel ER \& Benya RV 2008 International union of pharmacology. LXVIII. Mammalian bombesin receptors: nomenclature, distribution, pharmacology, signaling, and functions in normal and disease states. Pharmacological Reviews $601-42$. (https://doi.org/10.1124/pr.107.07108)

Lejeune H, Sanchez P, Chuzel F, Langlois D \& Saez JM 1998 Time-course effects of human recombinant luteinizing hormone on porcine Leydig cell specific differentiated functions. Molecular and Cellular Endocrinology 144 59-69. (https://doi.org/10.1016/S03037207(98)00153-1)

Lervik S, von Krogh K, Karlsson C, Olsaker I, Andresen O, Dahl E, Verhaegen S \& Ropstad E 2011 Steroidogenesis in primary cultures of neonatal porcine Leydig cells from Duroc and Norwegian Landrace breeds. Theriogenology 76 1058-1069. (https://doi.org/10.1016/j. theriogenology.2011.05.011)

Li X, Su J, Fang R, Zheng LC, Lei RP, Wang XY, Lei ZH, Jin MM, Jiao Y, Hou YL, et al. 2013 The effects of RFRP-3, the mammalian ortholog of $\mathrm{GnIH}$, on reproductive axis in vitro. Molecular and Cellular Endocrinology 372 65-72. (https://doi.org/10.1016/j.mce.2013.03.015)

Livak KJ \& Schmittgen TD 2001 Analysis of relative gene expression data using real-time quantitative PCR and the 2(T)(-Delta Delta C) method. Methods 25 402-408. (https://doi.org/10.1006/ meth.2001.1262)

Ma ZY, Su J, Guo TT, Jin MM, Li X, Lei ZH, Hou YL, Li XL, Jia CC, Zhang Z, et al. 2016 Neuromedin B and its receptor: gene cloning, tissue distribution and expression levels of the reproductive axis in pigs. PLOS ONE 11 e0151871. (https://doi.org/10.1371/journal. pone.0151871)

Malendowicz LK, Macchi C, Nussdorfer GG \& Nowak M 1996 The role of neuromedin B in the regulation of rat pituitary-adrenocortical function. Histology and Histopathology 11 895-897.

Matusiak D, Glover S, Nathaniel R, Matkowskyj K, Yang JX \& Benya RV 2005 Neuromedin B and its receptor are mitogens in both normal and malignant epithelial cells lining the colon. American Journal of Physiology: Gastrointestinal and Liver Physiology 288 G718-G728. (https://doi.org/10.1152/ajpgi.00156.2004)

Mauduit C, Goddard I, Besset V, Tabone E, Rey C, Gasnier F, Dacheux F \& Benahmed M 2001 Leukemia inhibitory factor antagonizes gonadotropin induced-testosterone synthesis in cultured porcine Leydig cells: sites of action. Endocrinology 142 2509-2520. (https:// doi.org/10.1210/endo.142.6.8177)

Meloche S \& Pouyssegur J 2007 The ERK1/2 mitogen-activated protein kinase pathway as a master regulator of the G1- to S-phase transition. Oncogene 26 3227-3239. (https://doi.org/10.1038/sj. onc.1210414)

Minamino N, Kangawa K \& Matsuo H 1983 Neuromedin B: a novel bombesin-like peptide identified in porcine spinal cord. Biochemical and Biophysical Research Communications 114 541-548. (https://doi. org/10.1016/0006-291X(83)90814-8)

Mo CH, Huang L, Cui L, Lv C, Lin DL, Song L, Zhu GQ, Li J \& Wang YJ 2017 Characterization of NMB, GRP and their receptors (BRS3, NMBR and GRPR) in chickens. Journal of Molecular Endocrinology 59 61-79. (https://doi.org/10.1530/JME-17-0020)

Moody TW, Staley J, Zia F, Coy DH \& Jensen RT 1992 Neuromedin B binds with high affinity, elevates cytosolic calcium and stimulates the growth of small-cell lung cancer cell lines. Journal of Pharmacology and Experimental Therapeutics 263 311-317.

Moody TW, Fagarasan M \& Zia F 1995 Neuromedin B stimulates arachidonic acid release, c-fos gene expression, and the growth of C6 glioma cells. Peptides 16 1133-1140. (https://doi.org/10.1016/01969781(95)00085-X)

Nakajima Y, Sato G, Ohno S \& Nakajin S 2005 Tributyltin chloride suppresses the P450cl7 transcription involved in testosterone production induced by gonadotropin stimulation in cultured pig 
Leydig cells. Environmental Toxicology and Pharmacology 20 11-17. (https://doi.org/10.1016/j.etap.2004.09.010)

Ohki-Hamazaki H 2000 Neuromedin B. Progress in Neurobiology 62 297-312. (https://doi.org/10.1016/S0301-0082(00)00004-6)

Ohki-Hamazaki H, Iwabuchi M \& Maekawa F 2005 Development and function of bombesin-like peptides and their receptors. International Journal of Developmental Biology 49 293-300. (https://doi. org/10.1387/ijdb.041954ho)

Pailhoux E, Mandon-Pepin B \& Cotinot C 2001 Mammalian gonadal differentiation: the pig model. Reproduction Supplement 58 65-80.

Park E, Kumar S, Lee B, Kim KJ, Seo JE, Choi HS \& Lee K 2017 Estrogen receptor-related receptor gamma regulates testicular steroidogenesis through direct and indirect regulation of steroidogenic gene expression. Molecular and Cellular Endocrinology 452 15-24. (https:// doi.org/10.1016/j.mce.2017.05.002)

Payne AH \& Youngblood GL 1995 Regulation of expression of steroidogenic enzymes in Leydig cells. Biology of Reproduction 52 217-225. (https://doi.org/10.1095/biolreprod52.2.217)

Ramos-Alvarez I, Moreno P, Mantey SA, Nakamura T, NucheBerenguer B, Moody TW, Coy DH \& Jensen RT 2015 Insights into bombesin receptors and ligands: highlighting recent advances. Peptides 72 128-144. (https://doi.org/10.1016/j.peptides.2015.04.026) Saito H, Ikeda R, Inoue K, Nagata S, Kitamura K, Minamino N, Kangawa K \& Miyata A 2012 Neuromedin B stimulates proliferation of mouse chondrogenic cell line ATDC5. Peptides 36 299-302. (https://doi.org/10.1016/j.peptides.2012.05.010)
Saito H, Nakamachi T, Inoue K, Ikeda R, Kitamura K, Minamino N, Shioda S \& Miyata A 2013 Autocrine effects of neuromedin B stimulate the proliferation of rat primary osteoblasts. Journal of Endocrinology 217 141-150. (https://doi.org/10.1530/JOE-120488)

Sayegh AI 2013 The role of bombesin and bombesin-related peptides in the short-term control of food intake. Progress in Molecular Biology and Translational Science 114 343-370.

Tsai CC, Chang LC, Lin KJ, Tey SL, Su YT, Liu CW, Tsai TR \& Huang SC 2015 Mechanism of bombesin-induced tonic contraction of the porcine lower esophageal sphincter. Scientific Reports 515879. (https://doi.org/10.1038/srep15879)

Wada E, Way J, Lebacq-Verheyden AM \& Battey JF 1990 Neuromedin B and gastrin-releasing peptide mRNAs are differentially distributed in the rat nervous system. Journal of Neuroscience 10 2917-2930. (https://doi.org/10.1523/JNEUROSCI.10-09-02917.1990)

Yeo CE, Kang WY, Seong SJ, Cho S, Lee HW, Yoon YR \& Kim HJ 2017 Neuromedin B and its receptor silencing suppresses osteoclast generation by modulating precursor proliferation via M-CSF/c-Fms/D-type cyclins. Experimental Cell Research 359 112-119. (https://doi.org/10.1016/j.yexcr.2017.08.003)

Zheng L, Su J, Fang R, Jin M, Lei Z, Hou Y, Ma Z \& Guo T 2015 Developmental changes in the role of gonadotropin-inhibitory hormone $(\mathrm{GnIH})$ and its receptors in the reproductive axis of male Xiaomeishan pigs. Animal Reproduction Science 154 113-120. (https:// doi.org/10.1016/j.anireprosci.2015.01.004)

Received in final form 26 March 2018

Accepted 9 April 2018

Accepted Preprint published online 9 April 2018 